\title{
Effect of intravenous ondansetron on QT interval prolongation in patients with cardiovascular disease and additional risk factors for torsades: a prospective, observational study
}

\author{
This article was published in the following Dove Press journal: \\ Drug, Healthcare and Patient Safety \\ 30 September 2011 \\ Number of times this article has been viewed
}

\author{
Matthew J Hafermann' \\ Rocsanna Namdar ${ }^{2}$ \\ Gretchen E Seibold ${ }^{2,3}$ \\ Robert Lee Page 2nd ${ }^{2,3}$ \\ 'University of Washington Medical \\ Center, Department of Pharmacy, \\ Seattle, WA; ${ }^{2}$ University of Colorado \\ Anschutz Medical Campus, School of \\ Pharmacy, Aurora, CO; ${ }^{3}$ University of \\ Colorado Hospital, Department of \\ Pharmacy, Aurora, CO USA
}

\begin{abstract}
Background: The 5-hydroxytryptamine type 3 antagonists, or setrons (eg, ondansetron), are commonly used for nausea and vomiting in the hospital setting. In 2001, droperidol was given a black box warning because it was found to prolong the QT interval and induce arrhythmias. The setrons share with droperidol the same potential proarrhythmic mechanisms, but limited data exist concerning their effects on the QT interval in individuals at high risk for torsades de pointes.
\end{abstract}

Methods: Forty hospitalized patients admitted for heart failure or acute coronary syndromes with one or more risk factors for torsades de pointes and an order for intravenous ondansetron $4 \mathrm{mg}$ were enrolled in this prospective, observational study. The QT interval corrected for heart rate (QTc) was obtained via a 12-lead electrocardiogram on admission and again 120 minutes after the first dose of ondansetron in order to determine the mean change in QTc following ondansetron exposure.

Results: The mean time interval between obtaining the baseline electrocardiogram and the second electrocardiogram following ondansetron administration was $3.5 \pm 2.14$ hours. In the total population, the QTc interval was prolonged by $19.3 \pm 18 \mathrm{msec}(P<0.0001) 120$ minutes after ondansetron administration. For patients with an acute coronary syndrome and those with heart failure, QTc was prolonged by $18.3 \pm 20 \mathrm{msec}(P<0.0001)$ and $20.6 \pm 20 \mathrm{msec}(P<0.0012)$, respectively. Following ondansetron exposure, $31 \%$ and $46 \%$ in the heart failure and acute coronary syndromes groups, respectively, met gender-related thresholds for a prolonged QTc. Conclusion: Our study found QTc prolongation due to ondansetron administration similar to that found in previous studies. When used in patients with cardiovascular disease (eg, heart failure or acute coronary syndromes) with one or more risk factors for torsades de pointes, ondansetron may significantly increase the QTc interval for up to 120 minutes after administration. From a patient safety perspective, patients who are at high risk for torsades de pointes and receiving ondansetron should be followed via telemetry when admitted to hospital.

Keywords: ondansetron, QT prolongation, patient safety, antiemetics

\section{Introduction}

Over the past two decades, the single most common cause of withdrawal or restriction of a medication that has already entered the market has been prolongation of the QT interval associated with polymorphic ventricular tachycardia or torsades de pointes. ${ }^{1}$ Nine structurally unrelated drugs marketed in the United States for a wide range of noncardiovascular indications have since been removed or had their availability severely restricted due to this form of toxicity. ${ }^{1,2}$ In the hospital setting, numerous risk factors for
Correspondence: Robert Lee Page 2 d and Physical Medicine, University of Colorado, Schools of Pharmacy and Medicine, Mail Stop C238, 12850 E Montview Blvd, V20-4I25, Aurora, CO 80045, USA

Tel +l 3037242626

Fax +I 3037242627

Email robert.page@ucdenver.edu 
drug-induced QT interval prolongation potentially leading to torsades de pointes exist, including hypokalemia, hypomagnesemia, bradycardia, genetic predisposition, associated heart disease, female gender, and use of drugs that either prolong the QT interval or disrupt the metabolism or distribution of QT-prolonging drugs. ${ }^{3}$ In the class of QT-prolonging drugs, intravenous administration of medications can also be associated with higher drug concentrations and greater cardiac exposure compared with oral dosing. ${ }^{3}$

In the postoperative setting, droperidol, as well as the 5-hydroxytryptamine type 3 receptor antagonists, or setrons (eg, ondansetron), have been found to be very effective antiemetics for prevention or treatment of nausea and vomiting. ${ }^{4}$ However, in 2001, the US Food and Drug Administration added a "black box" warning to the package labeling for droperidol regarding its potential proarrhythmic properties leading to QT prolongation. ${ }^{2}$ As a response to this warning, providers in the United States began to prescribe the setrons more widely due to patient safety issues. Furthermore, in 2006, generic ondansetron entered the US market, making the drug more widely available to providers and their patients. However, like droperidol, the setrons also possess the ability to block the myocardial $\mathrm{KCNH}$-encoded HERG (human ether-à-go-go related gene) potassium channel which, in theory, gives droperidol its proarrhythmic properties. ${ }^{5,6}$ The HERG channel mediates the $I_{\mathrm{Kr}}$ (rapid component of the delayed rectifier potassium current) which is essential for phase 3 of repolarization of the cardiac action potential. Inhibition of this current results in prolongation of the duration of the action potential and a prolonged QT interval., ${ }^{5,6}$ In addition, the setrons block sodium channels, resulting in lengthening of both depolarization and repolarization of the action potential. $^{5}$

While case reports have been published documenting the proarrhythmic potential of setrons in both adults and children, overall electrocardiographic data have been conflicting. ${ }^{7-11}$ Presently, only two prospective studies, conducted by the same investigators, have evaluated the effect of ondansetron, droperidol, and a combination of these agents on prolongation of the QT interval corrected for heart rate (QTc) at various time points following administration. ${ }^{12,13}$ In both studies, ondansetron was associated with a statistically significant increase in mean maximal QTc lengthening of about 17-20 msec $(P<0.0001)$. However, these findings were documented in patients who were either healthy volunteers or postoperative patients without additional risk factors for QTc prolongation. While these studies meet the criteria for assessing the effect of a drug on ventricular repolarization in humans established by the International Conference on Harmonization, their results do not always reflect a real world setting where the drug would be used in a patient with cardiovascular disease who may be at greater risk for QTc prolongation. ${ }^{14}$

Regarding patient safety, data generated in this patient population might assist health systems in their decisions to monitor the QTc interval more closely in those receiving setrons. The aim of this prospective observational study was to assess the effects of ondansetron on the mean QTc interval following the first dose in patients admitted to a coronary intensive care unit or step down unit with cardiovascular disease (eg, heart failure or acute coronary syndromes plus one additional risk factor for torsades de pointes).

\section{Methods}

\section{Subjects}

Study inclusion criteria consisted of admission with a principal diagnosis of either heart failure (ejection fraction $<40 \%$ ) or acute coronary syndromes to the University of Colorado Hospital, being a patient in the coronary intensive care unit or step down unit between December 21, 2010 and July 1, 2011, having a new medication order for $4 \mathrm{mg}$ intravenous ondansetron, and one of the following risk factors for torsades de pointes in the hospital setting: hypomagnesemia $(<1.0 \mathrm{mEq} / \mathrm{L})$ for $>24$ hours; hypokalemia $(<3.2 \mathrm{mEq} / \mathrm{L})$ for $>24$ hours; congenital long QT syndrome; baseline QTc $>500 \mathrm{msec}$; female gender; heart failure (ejection fraction $<40 \%$ ); acute coronary syndromes; old myocardial infarction; bradycardia ( $\leq 50$ beats per minute); or receiving more than one scheduled (not "as needed") medication with an accepted or possible risk for torsades de pointes as per the Education and Research at the University of Arizona. ${ }^{1,3,15}$ Patients were excluded if they were not placed on telemetry, had used ondansetron as a chronic medication or within the past four months, had already received a dose of ondansetron during their current hospitalization, or required a cardiac pacemaker. This study was reviewed and granted exempt status by the Colorado Multiple Investigation Review Board.

\section{Study design}

Patients were prospectively identified by a clinical pharmacist each morning by electronic pharmacy and medical admissions records. As part of hospital procedure, each patient admitted to the coronary intensive care unit or step down unit with a primary cardiovascular diagnosis had a baseline 12-lead electrocardiogram on admission conducted on the ward or in the emergency department. One hundred and 
twenty minutes after the first dose of slow push intravenous ondansetron, the patient's nurse obtained another 12-lead electrocardiogram. If the patient was also receiving a QTcprolonging medication, then the medication could not be given during this 120-minute time period. This 120-minute measurement interval was chosen because it was the middle of the dosing interval for ondansetron. The electrocardiographic readings were analyzed and the QTc calculated by a cardiologist who was also blinded to the intent of the study. QTc prolongation was defined as $>450 \mathrm{msec}$ for men and $>470$ msec for women. $^{3}$

The QT interval was measured by the following protocol. The anterior electrocardiogram lead in which the $\mathrm{T}$ wave had the largest amplitude was selected for QT interval measurement in each subject. ${ }^{3}$ The QT interval was measured from the onset of the QRS complex to the end of the T wave, which was defined according to the criteria of Lepeschkin and Surawicz. ${ }^{16}$ Because a notched $\mathrm{T}$ wave could represent T-U fusion, according to Lepeschkin and Surawicz, the intersection of the tangent to the downslope of the major repolarization wave with the isoelectric line was used in the presence of a T-U wave. ${ }^{16}$ The QT interval was corrected for heart rate according to the formula of Bazett $(\mathrm{QTc}=\mathrm{QT} / \sqrt{\mathrm{R}} \times \mathrm{R})$.

\section{Statistical analysis}

Results are expressed as the mean \pm standard deviation. To detect a QTc change from baseline greater than $10 \mathrm{msec}$ with $\alpha$ and $\beta$ risks of 0.05 and 0.20 , respectively, and assuming a standard deviation of QTc change of $10 \mathrm{msec}$, a minimum of 10 subjects was needed. However, 40 patients were analyzed so as to establish a normal distribution. Comparison of QTc before and after ondansetron exposure was analyzed using the Student's paired $t$-test. All other variables were evaluated using descriptive statistics. All analyses were conducted using SAS version 9.2 (SAS Institute Inc, Cary, NC).

\section{Results}

Data were collected and analyzed for 40 patients (16 with a principal diagnosis of heart failure and 24 with a principal diagnosis of acute coronary syndromes). Table 1 summarizes the demographic and clinical characteristics of the patients studied. The mean age was 55 years in both the heart failure and acute coronary syndromes groups, with $50 \%$ of patients being women. In patients with heart failure, three patients had a baseline QTc that was already prolonged (range $0.52-0.57 \mathrm{msec}$ ) as did five patients in the acute coronary syndromes group (range $0.50-0.57 \mathrm{msec}$ ). The majority of risk factors for QTc prolongation in both groups consisted
Table I Demographic and clinical characteristics of patients

\begin{tabular}{|c|c|c|}
\hline \multirow[t]{2}{*}{ Characteristic } & \multicolumn{2}{|c|}{$\begin{array}{l}\text { Principal diagnosis on } \\
\text { admission }\end{array}$} \\
\hline & $\begin{array}{l}\text { Heart failure } \\
(n=16)\end{array}$ & $\begin{array}{l}\text { ACS } \\
(n=24)\end{array}$ \\
\hline \multicolumn{3}{|l|}{ Demographics } \\
\hline Age (mean \pm SD years) & $55 \pm 18$ & $54 \pm 14$ \\
\hline Female (\%) & $8(50)$ & $12(50)$ \\
\hline \multicolumn{3}{|l|}{ Comorbidities (\%) } \\
\hline Anemia & $3(19)$ & I (4) \\
\hline COPD/asthma & $2(13)$ & $4(17)$ \\
\hline Chronic pain & $2(13)$ & $2(8)$ \\
\hline Dementia & $2(13)$ & I (4) \\
\hline Depression & $6(38)$ & $6(25)$ \\
\hline Diabetes & $4(25)$ & $4(17)$ \\
\hline DVT/PE & $6(38)$ & $4(17)$ \\
\hline Old myocardial infarction & $5(3 I)$ & $5(2 I)$ \\
\hline Heart failure & $16(100)$ & $5(2 I)$ \\
\hline Hypertension & $6(38)$ & $13(54)$ \\
\hline Hyperlipidemia & $5(3 I)$ & $20(83)$ \\
\hline Osteoarthritis & I (6) & $2(8)$ \\
\hline Pneumonia & $2(13)$ & I (4) \\
\hline Renal insufficiency & $3(19)$ & $2(8)$ \\
\hline Schizophrenia & $2(13)$ & $2(8)$ \\
\hline Seizure disorder & $2(13)$ & I (4) \\
\hline Stroke/transient ischemic attack & I (6) & I (4) \\
\hline Chronic urinary tract infections & $I(6)$ & $0(0)$ \\
\hline \multicolumn{3}{|l|}{ Risk factors for QTc prolongation (\%) } \\
\hline Acute coronary syndromes & $0(0)$ & $24(100)$ \\
\hline Bradycardia & I (6) & $\mathrm{I}(4)$ \\
\hline Congenital long QTc syndrome & $0(0)$ & $0(0)$ \\
\hline Female gender & $8(50)$ & $12(50)$ \\
\hline Heart failure & $16(100)$ & $5(21)$ \\
\hline Hypokalemia & $6(38)$ & $13(54)$ \\
\hline Hypomagnesemia & $5(3 I)$ & $5(2 I)$ \\
\hline Old myocardial infarction & $5(3 I)$ & $5(2 I)$ \\
\hline QTc $>500$ msec at baseline ${ }^{\dagger}$ & $3(19)$ & $5(2 I)$ \\
\hline Receiving $>$ I QTc-prolonging medication & $10(63)$ & $15(63)$ \\
\hline $\begin{array}{l}\text { Number of patients with only I risk } \\
\text { factor for QTc prolongation* }\end{array}$ & $9(56)$ & $8(33)$ \\
\hline $\begin{array}{l}\text { Number with } \geq 2 \text { risk factors for QTc } \\
\text { prolongation* }\end{array}$ & $7(44)$ & $16(67)$ \\
\hline
\end{tabular}

Notes: *Not including principal diagnosis of either heart failure or acute coronary syndromes; tsee Table 2 for specific medications.

Abbreviations: ACS, acute coronary syndromes; COPD, chronic obstructive pulmonary disease; DVT, deep vein thrombosis; PE, pulmonary embolism; QTc, QT interval corrected for heart rate; SD, standard deviation.

of receiving at least one medication that could potentially prolong QTc, female gender, and hypokalemia. Not including the principal diagnosis as a risk factor, $56 \%$ of patients with heart failure had only one risk factor for QTc prolongation, compared with $33 \%$ of patients with acute coronary syndromes. Table 2 lists the concomitant QTc-prolonging medications, their risk for torsades de pointes as per the Center for Education and Research at the University of Arizona, the length of time the patient had been receiving 
Table 2 Description of QTc-prolonging medications

\begin{tabular}{|c|c|c|c|c|}
\hline Scheduled medication & Patients, n (\%) & Risk of QTc prolongation* & $\begin{array}{l}\text { Time receiving medication prior } \\
\text { to ondansetron exposure }\end{array}$ & $\begin{array}{l}\text { Half-life } \\
\text { (hours) }\end{array}$ \\
\hline Levofloxacin & $4(10)$ & Possible & 5 days to 14 days & $6-8$ \\
\hline Citalopram & $8(20)$ & Possible & I month to 5 years & 35 \\
\hline Erythromycin ${ }^{\dagger}$ & $4(10)$ & Accepted & 5 days to 10 days & $4.6-7.8$ \\
\hline Haloperidol & I (3) & Accepted & 3 days to 4 days & 14 \\
\hline Methadone & $4(10)$ & Accepted & I year to 3 years & $7-60$ \\
\hline Ranolazine & $8(20)$ & Possible & 45 days to 3 years & $7-9$ \\
\hline Risperidone & $3(8)$ & Possible & 1 year to 5 years & $3-20$ \\
\hline Quetiapine & $2(5)$ & Possible & 6 months to 4 years & 6 \\
\hline Tizanidine & $3(8)$ & Possible & 8 days to 3 years & 2.5 \\
\hline Ziprasidone & $3(8)$ & Possible & 2 months to 3 years & $2-7$ \\
\hline Venlafaxine & $5(13)$ & Possible & 2 months to 4 years & 5 \\
\hline
\end{tabular}

Notes: Used for gastrointestinal motility in patients with diabetes. *QTc risk as determined by the Center for Education and Research at the University of Arizona.

Abbreviation: QTc, QT interval corrected for heart rate.

the medication prior to ondansetron exposure, and the half-life of the drug. All QTc-prolonging medications had been initiated prior to hospital admission (range 3 days to 5 years), were scheduled medications and not given as needed, and were at steady-state as per their half-half. As seen in Table 3, the mean and median baseline QTc for patients with heart failure were $443 \pm 53 \mathrm{msec}$ and $435 \mathrm{msec}$, respectively, and $444 \pm 45 \mathrm{msec}$ and $430 \mathrm{msec}$, respectively, for patients with acute coronary syndromes. One hundred and twenty minutes after ondansetron administration, the mean and median baseline QTc for patients with heart failure increased to $466 \pm 60 \mathrm{msec}$ and $450 \mathrm{msec}$, respectively, and to $463 \pm 45 \mathrm{msec}$ and $450 \mathrm{msec}$, respectively, for patients with acute coronary syndromes. The mean difference in time interval between obtaining the baseline electrocardiogram and the second electrocardiogram following ondansetron administration was $3.5 \pm 2.14$ (range $0.5-8$ ) hours. Compared with baseline, the mean change in QTc increased significantly by $20.6 \pm 20 \mathrm{msec}(P<0.0012), 18.3 \pm 20 \mathrm{msec}$ $(P<0.0001)$, and $19.30 \pm 18 \mathrm{msec}(P<0.0001) 120 \mathrm{~min}-$ utes after ondansetron administration in patients with heart failure, acute coronary syndromes, and the total population, respectively. According to gender-related thresholds, five patients $(31 \%)$ in the heart failure group and 11 patients $(46 \%)$ in the acute coronary syndromes group met the criteria for prolonged QTc following ondansetron administration. No patients experienced torsades de pointes during their hospital admission.

\section{Discussion}

Our data are consistent with those of two previously published studies evaluating the QTc prolongation effect of ondansetron. ${ }^{12,13}$ In a prospective single-blind study, Charbit et al evaluated 85 patients with postoperative nausea and vomiting who were allocated to receive either $0.75 \mathrm{mg}$ droperidol or $4 \mathrm{mg}$ ondansetron intravenously. ${ }^{12}$ Electrocardiographic recordings were obtained before administration and then again at minutes 1, 2, 3, 5, 10, and 15 afterwards. According to gender-related thresholds, the incidence of QTc prolongation was $20 \%$ and $23 \%$ in the ondansetron and droperidol groups, respectively. The investigators found a significant increase in mean QTc interval during the 15 minutes after

Table 3 Summary of QTc interval changes

\begin{tabular}{|c|c|c|c|}
\hline \multirow[t]{3}{*}{ QTc outcomes } & \multicolumn{2}{|c|}{ Principal diagnosis } & \multirow{3}{*}{$\begin{array}{l}\text { Total population } \\
n=40\end{array}$} \\
\hline & Heart failure & ACS & \\
\hline & $\mathbf{n}=16$ & $\mathbf{n}=\mathbf{2 4}$ & \\
\hline Baseline, mean $\pm \mathrm{SD}$, msec & $443 \pm 53$ & $444 \pm 45$ & $444 \pm 47$ \\
\hline Baseline, median, msec & 435 & 430 & 430 \\
\hline Baseline, range, msec & $360-570$ & $390-570$ & $360-570$ \\
\hline Two hours post-drug, mean $\pm \mathrm{SD}$, msec & $466 \pm 60$ & $463 \pm 45$ & $464 \pm 50$ \\
\hline Two hours post-drug, median, msec & 450 & 450 & 450 \\
\hline Two hours post-drug, range, msec & $410-590$ & $420-580$ & $410-590$ \\
\hline Mean change $\pm \mathrm{SD}$, msec & $20.6 \pm 20 *$ & $18.3 \pm 20 * *$ & $19.30 \pm 18 * *$ \\
\hline
\end{tabular}

Notes: $* p<0.0012 ; * * p<0.0001$.

Abbreviations: ACS, acute coronary syndromes; SD, standard deviation; QTc, QT interval corrected for heart rate. 
antiemetic drug administration in both groups. The maximal mean QTc interval lengthening was observed at 3 minutes after ondansetron administration, with a mean maximal lengthening of $20 \pm 13 \mathrm{msec}(P<0.0001)$ using Bazett's QT correction formula. When using the Fridericia correction formula, the QTc interval changes were similar to those found by Bazett's correction formula. In a subset of eight patients, electrocardiograms were repeated up to 3 hours following drug exposure. In both groups, there was a statistically significant reduction in QTc interval when compared with baseline QTc $(P<0.05)$.

In their second study, Charbit et al randomized 16 healthy volunteers to receive either placebo, $1 \mathrm{mg}$ of intravenous droperidol, $4 \mathrm{mg}$ of intravenous ondansetron, or $1 \mathrm{mg}$ of intravenous droperidol plus $4 \mathrm{mg}$ of intravenous ondansetron in a double-blind crossover design. ${ }^{13}$ At intervals of one minute for the first 15 minutes and then at minutes 20, 30, 45, 60, $90,120,240$, and 600 after the beginning of drug administration, 10-second digital electrocardiograms were recorded. Compared with placebo, the mean maximal difference in change in QTc values using the Fridericia correction formula were $25 \pm 8 \mathrm{msec}$ and $17 \pm 10 \mathrm{msec}$, and $42 \pm 21 \mathrm{msec}$ and $24 \pm 12$ msec using Bazett's QT correction formula after droperidol and ondansetron administration, respectively. When evaluating time, volunteers receiving intravenous ondansetron had QT interval prolongation until minute 4 , and then again at minutes 7,8 , and 11 . In both studies, the investigators concluded that, under controlled conditions, ondansetron induced significantly marked prolongation of the QTc interval. ${ }^{12,13}$

In our study, using Bazett's formula for QT correction, we found that patients with heart failure or acute coronary syndromes with additional risk factors for QT prolongation had significant prolonging of their QTc interval by $20.6 \pm 20 \mathrm{msec}$ $(P<0.0012)$ and $18.3 \pm 20 \mathrm{msec}(P<0.0001)$, respectively, which was similar to the mean maximal changes in QTc seen in the other two studies. ${ }^{12,13}$ However, in our study, this prolongation was only seen at 120 minutes after administration of ondansetron because we did not measure QTc before or beyond this time period. We hypothesize that this may be due to the fact that all our patients had underlying heart disease, which is considered to be one of most important nonmodifiable risk factors for QTc prolongation. ${ }^{1,2}$ Cardiac dilatation from long-standing heart failure can result in abnormal automaticity. Anaerobic metabolism in ischemic myocardial tissue following myocardial infarction can raise the resting membrane potential and ultimately lead to an abnormal impulse condition. ${ }^{1,2}$ Additionally, the half-life of ondansetron in healthy volunteers is 5.7 hours, so adequate drug was still available within the central compartment to have a potential impact on myocardial tissue. ${ }^{17}$

Our study has several of the limitations associated with observational data. First, selection bias could exist. However, patients were identified consecutively and enrolled into the study according to inclusion criteria in the order that they were admitted. Secondly, a mean period of $3.5 \pm 2.14$ hours existed between obtaining a baseline electrocardiogram to the second electrocardiogram following intravenous ondansetron administration, during which patient's symptoms could deteriorate or improve, thereby impacting the QTc interval during that window of time. Third, based on animal models, rapid infusion of QTc-prolonging medications may be more likely to cause arrhythmias than slower infusions. ${ }^{3}$ However, at our institution, it is hospital policy that ondansetron be administered via slow intravenous push (eg, over five or more minutes). Fourth, we were not able to obtain multiple consecutive electrocardiographic measures because this was considered a patient safety/quality control initiative and could impede nursing work flow in the coronary intensive care unit and step down settings. This was stipulated by our institutional medication use evaluation committee. Fifth, we used Bazett's formula for correcting the QTc for varying heart rate. While this is the most commonly used method in clinical practice, it has been shown to overcorrect at short RR intervals and to undercorrect at long RR intervals. ${ }^{1}$ Finally, our data are reflective only of the intravenous formulation of ondansetron, and cannot be generalized to oral dosing. ${ }^{3}$

\section{Conclusion}

Despite these limitations, the results of our study add to the literature showing that intravenous ondansetron in doses approved by the Food and Drug Administration can significantly prolong the QTc interval. As per the Center for Education and Research at the University of Arizona, ondansetron is a member of the risk category of "possible drugs" that could prolong the QTc interval, leading to torsades de pointes. ${ }^{15}$ In patients admitted for either heart failure or acute coronary syndromes with at least one additional risk factor for torsades de pointes, we found that this effect could be seen at least 120 minutes following drug exposure. When considering using ondansetron for long-term administration in the inpatient setting, patients with cardiovascular disease who are at high risk for drug-induced torsades de pointes should at least be monitored via telemetry. From a patient safety perspective, ondansetron should be added to the clinician's list of drugs that can possibly prolong the QTc interval. 


\section{Disclosure}

The authors report no conflicts of interest in this work.

\section{References}

1. Barnes BJ, Hollands JM. Drug-induced arrhythmias. Crit Care Med. 2010;38(6 Suppl):S188-S197.

2. Roden DM. Drug-induced prolongation of the QT interval. $N$ Engl J Med. 2004;350(10):1013-1022.

3. Drew BJ, Ackerman MJ, Funk M, et al. Prevention of torsade de pointes in hospital settings: a scientific statement from the American Heart Association and the American College of Cardiology Foundation. Circulation. 2010;121(8):1047-1060.

4. Apfel CC, Korttila K, Abdalla M, et al. A factorial trial of six interventions for the prevention of postoperative nausea and vomiting. $N$ Engl $J$ Med. 2004;350(24):2441-2451.

5. Kuryshev YA, Brown AM, Wang L, Benedict CR, Rampe D. Interactions of the 5-hydroxytryptamine 3 antagonist class of antiemetic drugs with human cardiac ion channels. J Pharmacol Exp Ther. 2000; 295(2):614-620.

6. Schwoerer AP, Blutner C, Brandt S, et al. Molecular interaction of droperidol with human ether-a-go-go-related gene channels: prolongation of action potential duration without inducing early afterdepolarization. Anesthesiology. 2007;106(5):967-976.

7. Baguley WA, Hay WT, Mackie KP, Cheney FW, Cullen BF. Cardiac dysrhythmias associated with the intravenous administration of ondansetron and metoclopramide. Anesth Analg. 1997;84(6):1380-1381.

8. Buyukavci M, Olgun H, Ceviz N. The effects of ondansetron and granisetron on electrocardiography in children receiving chemotherapy for acute leukemia. Am J Clin Oncol. 2005;28(2):201-204.
9. Keller GA, Ponte ML, Di Girolamo G. Other drugs acting on nervous system associated with QT-interval prolongation. Curr Drug Saf. 2010;5(1):105-111.

10. McKechnie K, Froese A. Ventricular tachycardia after ondansetron administration in a child with undiagnosed long QT syndrome. Can J Anaesth. 2010;57(5):453-457.

11. Miller DR. Arrhythmogenic potential of antiemetics: perspectives on risk-benefits. Can J Anaesth. 2003;50(3):215-220.

12. Charbit B, Albaladejo P, Funck-Brentano C, Legrand M, Samain E, Marty J. Prolongation of QTc interval after postoperative nausea and vomiting treatment by droperidol or ondansetron. Anesthesiology. 2005; 102(6): 1094-1100

13. Charbit B, Alvarez JC, Dasque E, Abe E, Demolis JL, Funck-Brentano C. Droperidol and ondansetron-induced QT interval prolongation: a clinical drug interaction study. Anesthesiology. 2008;109(2):206-212.

14. European Medicines Agency. The clinical evaluation of QT/ATc interval prolongation and proarrhythmic potential for non-antiarrhythmic drugs. Available at: http://www.ema.europa.eu/docs/en_GB/document_ library/Scientific_guideline/2009/09/WC500002879.pdf. Accessed August 28, 2011.

15. ARIZONA CERT-Center for Education and Research Therapeutics. QT Drug Lists. Available at: http://www.azcert.org/medical-pros/drug-lists/ bycategory.cfm. Accessed August 28, 2011.

16. Lepeschkin E, Surawicz B. The measurement of the Q-T interval of the electrocardiogram. Circulation. 1952;6(3):378-388.

17. Ondansetron injection, USP package insert. Bedford, OH: Bedford Laboratories; 2010.
Drug, Healthcare and Patient Safety

\section{Publish your work in this journal}

Drug, Healthcare and Patient Safety is an international, peer-reviewed open-access journal exploring patient safety issues in the healthcare continuum from diagnostic and screening interventions through to treatment, drug therapy and surgery. The journal is characterized by the rapid reporting of reviews, original research, clinical, epidemiological and

\section{Dovepress}

post-marketing surveillance studies, risk management, health literacy and educational programs across all areas of healthcare delivery. The manuscript management system is completely online and includes a very quick and fair peer-review system. Visit http://www.dovepress.com/ testimonials.php to read real quotes from published authors. 